\title{
NICANOR PARRA EN LA REVISTA ARÚSPICE
}

\section{JAIME QUEZADA*}

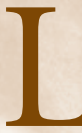

A REVISTA Arúspice (que fundé y dirigí en mi tiempo de estudiante de Derecho en la Universidad de Concepción) fue el órgano de difusión del grupo del mismo nombre, integrado por jóvenes autores durante la década de los años 1960-1970. Se publicaron estacionalmente ocho números. Su primer número apareció en el otoño-invierno de 1964. Y el último en el otoño-invierno de 1968. Se publicaba con el auspicio y patrocinio del Departamento de Asuntos Estudiantiles de dicha Universidad. Su epígrafe era una frase de Picasso: Cuando no tengo azul pongo rojo. Y otro de Julio Cortázar, enviado por él en una carta: Al fuego, cronopios, al fuego.

En su primer número, la revista hacía público una especie de declaración de principios:

Arúspice quiere ser un bloque de trabajo consciente y productivo. Guía. Porque la afinidad amistosa y la interrelación pueden constituir un humus fértil. Y la forma de trabajo que se ha debido elegir es la libertad. Un grupo que exista libremente en cada uno de sus miembros. Sin academicismos asfixiantes ni organizaciones. Con afán de amplia visión, con carácter de necesidad...

Como dato significativo cabe destacar que en su número doble 7-8 (otoño-invierno 1968) publica los primeros “Artefactos” de Nicanor Parra:

* Poeta, ensayista y crítico literario. Estudió Derecho y Literatura en la Universidad de Concepción. Poemas de las cosas olvidadas (1965) fue su primer libro publicado. Santiago, Chile. Correo: jaime.quezadaruiz@gmail.com 
"Esperando micro", "Endecasílabo", "Los tres ladrones", "El anciano difícil”, "Aviso", "Advertencia", "Hijo", "Vals interruptus", escritos de su puño y letra, y que el mismo Nicanor nos entregó generosamente, después de un almuerzo en su casa de La Reina, como colaboración a la revista. Y una dedicatoria: A / Jaime Quezada / Constructor de Artefactos / Nicanor Parra / Gásfiter / 67 / La Reina. (En la posdata de una carta de Jorge Teillier, y fechada en agosto de 1968, me decía: "He hablado con Nicanor Parra, que está muy orgulloso de ser el centro de la revista Arúspice en su última entrega. Te envía saludos cariñosos").

"Los artefactos resultaron de la explosión del antipoema", nos decía Nicanor. "Son fragmentos de una granada en su alta velocidad. Salen en distintas direcciones y matan a los tipos que están por ahí. Tienen su gran capacidad de energía. Claro que algunos de mis artefactos se los debo a Luis Oyarzún. Él los decía mientras caminábamos por los patios de la Universidad. Yo sólo les puse mi nombre, como éste, por ejemplo: "Estoy con el agua al pescuezo / si me siento me ahogo".

Aviso

Estudiantes de Humanidades

En vez de escribir palabrotas

En los muros de las letrinas

Escriban dios

Escriban virgensantísima.

HiJO

Dónde estás

Oye los sabios consejos de tu padre

Cree más en la teoría de la papa caliente

Que en los estudios de idiomas por correspondencia.

LOS TRES LADRONES

El buen Ladrón

El mal Ladrón

Y el del Medio.

ESPERANDO MICRO

Mientras espera micro

Diga al revés las siguientes palabras

Adán

Eva 
Diga también al revés esta otra:

God.

Además de sus "artefactos", la revista destaca en sus páginas centrales el poema "Un hombre", texto entonces recién escrito e inédito de Nicanor. El sencillo, asombroso y memorable poema mereció de inmediato un todavía más asombroso y eufórico comentario del crítico Ignacio Valente ("Sobre un poema de Parra") y a toda página en su columna dominical llamando a los antologistas de todo el mundo a unirse en la selección de "este siniestro y hermoso poema" (El Mercurio, Santiago, 4 de agosto, 1968). Entre lo fervoroso y lo analítico, Valente no se resiste a citar completo el sencillo y memorable poema, cosa no común ni frecuente en sus comentarios críticos, y en hora buena, sin duda, toda vez que Arúspice tenía el privilegio de ser la primera y única revista en publicarlo. Al igual yo, aquí y ahora, no me resisto a citar-siquiera en parte- el también memorable e iluminado comentario:

Dice Ignacio Valente:

Hay una novela de Kafka, absurda y conmovedora, hay una parábola trágica de la condición humana, hay la substancia de muchos ensayos en este breve poema. Sus versos, lacónicos, convencionales de intento, inducen a pensar en esta nunca bien ponderada función de la palabra poética: decir un mundo en una estrofa, encerrar en un mínimo sistema verbal un máximo de amplitud humana, una experiencia que el novelista debe desarrollar en múltiples secuencias narrativas, o que el hombre de pensamiento debe refractar en las plurales dimensiones de su análisis. A un poeta, más cerca de los dioses, han de bastarle pocas líneas para revelar la existencia en la palabra...

El lector inadvertido atribuirá a este poema la forma de la prosa, su despreocupación verbal, su continuidad narrativa. Parece, incluso, el resumen apretado de un relato, la sinopsis de un cuento. Sin embargo, frente al carácter abstracto y esquelético que una tal síntesis tendría, este poema se arroga una estilización tan concreta de la existencia, una carga humana tan ostensible y exacta en cada verso, que incluso parece describir la vida con lujo de detalles. La condición humana en una breve anécdota. La transferencia de los fines, la fuga de los objetivos, lo que la vida hace con nosotros al margen de nosotros mismos entre risas y llantos vacíos, la alienación tragicómica de la voluntad... Es una parábola, no una alegoría. Tiene la concreción esencial de un poema, no el dispendio comprimido de un relato. 
Los materiales de construcción de este poema acentúan la impresión de flaccidez prosística, pero también, por eso mismo, el valor de su triunfo expresivo. Son frases hechas, giros convencionales, elementos típicos y genéricos que aun dentro de un relato resultarían obvios, fáciles, lugares comunes. Pero en el poema, y a fuerza de exacerbar su convencionalismo y su vulgaridad, tales expresiones se tornan esenciales, dramáticas, y revisten una figura que es tanto más terrible cuanto más anónima y universal. Esta es la maestría del poeta: bordear en todo momento una abstracción trivial, una alegórica vulgaridad, y extraer de esos materiales una historia que tiene la realidad inapelable de las situaciones singulares, así como la universalidad que esas situaciones cobran en la poesía verdadera.

Su fondo de experiencia, tan evidente, concentra la materia de amplias disquisiciones de un Freud, un Sastre, un Hidegger. El poeta nos hace reconocible y próximo lo que los conceptos nos han hecho difuso y lejano. Su descarado pesimismo, sin embargo, se matiza con un elemento diverso y no menos indudable: lo conmovedor, casi lo patético. Hay aquí un sello del más auténtico Parra: la piedad, la piedad conmovida y reverencial por la condición humana.

Este protagonista que da su título al poema -"Un hombre"- no es el sujeto despreciable de la pasión inútil, no es el animalillo sexual o el neurótico, no es la abstracción del ser para la muerte, no es el abominable individuo caído en la cotidianidad. Es un hombre, el ser compasible que abrazamos en nuestro prójimo, un personaje que por encima de su sonámbula alienación vale más que todos los reinos de este mundo, y sobre quien, dormido en el escritorio después de la grotesca sucesión de contingencias, se inclinan la misericordia humana y la piedad de los ángeles. ¿No prolonga este poema una resonancia ulterior, una imagen más allá de sí mismo, y en esta imagen los ángeles consuelan al pobre, al atribulado, al enajenado protagonista de este juego de títeres?

Antologistas de todo el mundo, uníos en la selección de este siniestro y hermoso poema de Nicanor Parra.

$\mathrm{Al}$ inicio de dicho asombroso comentario para tan asombroso poema, que venía a ser, sin duda también un reconocimiento público a la revista, Valente señalaba que el poema de Nicanor Parra "se publica en páginas circundado por versos de jóvenes émulos que ostentan su influjo visible, si bien se acercan más a la mecánica del antipoema que no al humor personal e irrepetible de su creador". Entre esos "jóvenes émulos" figuraban -y según el orden correlativo de páginas- Gonzalo Millán ("Reversos"), Floridor Pérez ("Poemario en tres actos"), Waldo Rojas ("Ventana"), Jaime Quezada ("Jonás redimido"), Hernán Lavín Cerda ("Lo juro"), Omar Lara (“Gestos”), Edgardo Jiménez (“Desvaríos”). 
La edición, en una tirada de 500 ejemplares, numerados, publicaba en sus primeras páginas un texto ensayístico del escritor cubano José Lezama Lima ("Responsabilidad del intelectual ante los problemas del mundo subdesarrollado", leído recientemente en un Congreso Cultural de La Habana, enero 1968) y hacia sus páginas finales dos extensos poemas de Gonzalo Rojas: "A la salud de André Breton" y "El comandante"; textos que su autor incluiría años después en su libro Del relámpago (1981).

Por esta misma fecha de la publicación de "Arúspice", y por algún "agravio pendenciero", Gonzalo Rojas escribiría Gracias y desgracias del antipoe$t a$, un iracundo texto sobre Nicanor Parra que prontamente lo publica la ideológica revista santiaguina "Punto Final" y la nortina revista de poesía Tebaida, después. Aunque el mismo Gonzalo lo rescatará -aun pasen treinta años- en su libro madrileño Metamorfosis de lo mismo (Visor, 2000) con la siguiente nota introductoria: "Versaina ya remota y escrita en una hora; respuesta a algún agravio pendenciero. Quiérase ver en ella lo que fue: ligereza y salud, un ejercicio punitivo y airoso, más riente que áspero, un juego a eso de mojarle al otro la oreja, de niño a niño. Que lo digan Góngora o Quevedo".

También, y a manera de dato historicista, es relevante señalar que durante los meses iniciales de 1970, Arúspice preparaba el número 9-10 de su publicación, dedicado íntegramente a Pablo Neruda. El vate de Isla Negra, por intermedio de su secretario -el poeta Homero Arce- nos había hecho llegar varios de sus poemas recientes e inéditos: "La piel de abedul", "Con Quevedo en primavera", "Llama el océano", "Los perdidos del bosque", "Muchas gracias". (Los mismos poemas que irían a su libro póstumo Jardín de invierno, 1974).

Pero nuevos vientos, o mejor, vientos revueltos (por no decir huidobrianamente contrarios), soplaban en la Universidad de Concepción. De ahí que el poeta Jorge Teillier, que había comentado auspiciosamente los números anteriores de Arúspice ("Es grato hablar de esta revista que cuenta ya con un sólido respaldo y buena difusión") en la santiaguina y docta revista Mapocho, se preguntaba con cierta alarma en marzo de 1970: “QQué suerte correrá Arúspice?"

El número nerudiano de la revista no llegó a concretarse. Y -de hechosu última publicación fue la dedicada principalmente a Nicanor Parra en su número de otoño-invierno de 1968. Por lo demás, Arúspice concluía ya un ciclo o etapa de actividad poética y literaria en una (mi) Universidad de Concepción que, hasta esa fecha, siempre nos estimuló y nos abrió amplias y plurales posibilidades creadoras. 


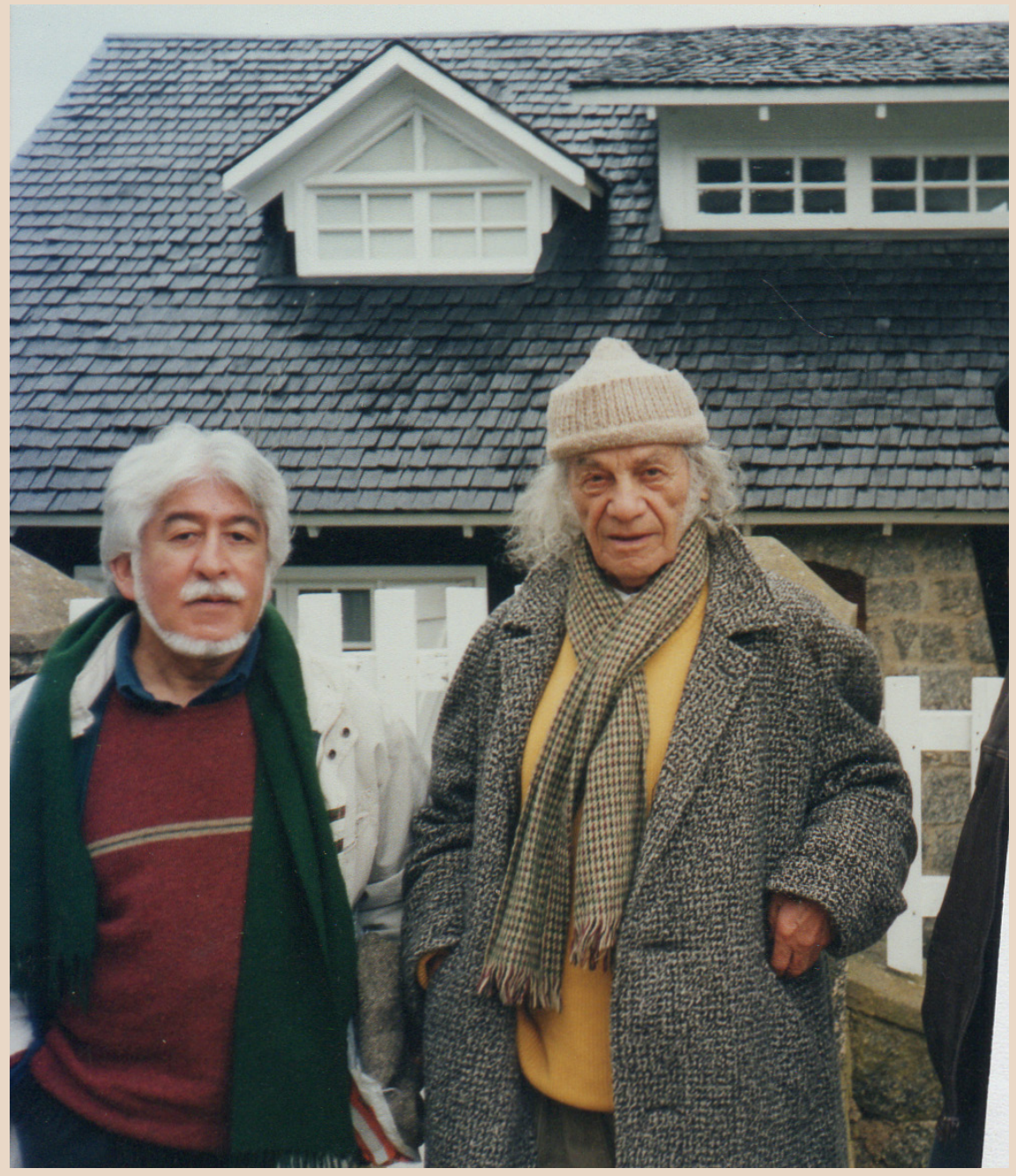

Jaime Quezada y Nicanor Parra, Las Cruces, agosto 2013. 
Algunos años después de Arúspice, Ediciones Nueva Universidad publica Artefactos (Santiago, 1972), un nuevo, sorprendente y certero libro de Nicanor Parra. En verdad, se trata aquí de poemas-objetos, conjunto de tarjetas que recogen aforismos, sentencias, dichos populares, inscripciones en muros, servicios higiénicos, fuentes de soda, y todo un decir de escritura cotidiana que en lenguaje de Parra se transforma en parlamentos dramáticos. "Los terribles artefactos de Parra", dice la crítica: "Una exposición de su verdadero pensamiento político", dicen otros. Dibujos, fotografías, juegos gráficos se interrelacionan con los explosivos textos, constituyendo así un discurso verbal y visual en su máxima expresión y velocidad del lenguaje poético.

Aquellos otros breves e incisivos primeros textos llamados "artefactos", o "partículas elementales" cargadas de energía, se quedarán definitivamente en las páginas de Arúspice para revelación, interés y curiosidad de la cada vez más ecuménica y admirativa biobibliografía parriana. Así, Nicanor Parra que venía bajando del Olimpo parecía, a su vez, estar más cerca de los dioses.

\section{UN HOMBRE}

La madre de un hombre está gravemente enferma

Parte en busca del médico

Llora

En la calle ve a su mujer acompañada de otro hombre

Van tomados de la mano

Los sigue a corta distancia

De árbol en árbol en árbol

Llora

Ahora se encuentra con un amigo de juventud

¡Años que no nos veíamos!

Pasan a un bar

Conversan, ríen

El hombre sale a orinar al patio

Ve una muchacha joven

Es de noche ella lava los platos

El hombre se acerca a la joven

La toma de la cintura

Bailan vals

Juntos salen a la calle

Ríen 
Hay un accidente

La muchacha ha perdido el conocimiento

El hombre va a llamar por teléfono

Llora

Llega a una casa con luces

Pide teléfono

Alguien lo reconoce

Quédate a comer hombre

No

Dónde está el teléfono

Come, hombre, come

Después te vas

Se sienta a comer

Bebe como un condenado

Ríe

Lo hacen recitar

Recita

Se queda dormido debajo de un escritorio. 